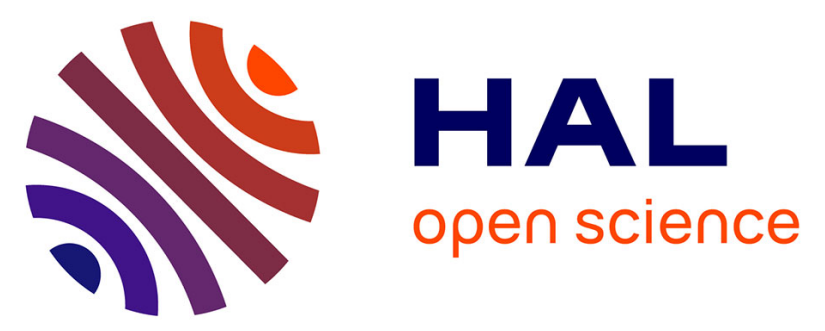

\title{
High-Resolution Power Density Measurement Technique in the Near-Field Accounting for Antenna/Body Coupling at Millimeter-Waves
}

\author{
Massinissa Ziane, Maxim Zhadobov, Ronan Sauleau
}

\section{- To cite this version:}

Massinissa Ziane, Maxim Zhadobov, Ronan Sauleau. High-Resolution Power Density Measurement Technique in the Near-Field Accounting for Antenna/Body Coupling at Millimeter-Waves. IEEE Antennas and Wireless Propagation Letters, 2021, 20 (11), pp.2151-2155. 10.1109/lawp.2021.3087019 . hal-03328820

HAL Id: hal-03328820

https://hal-univ-rennes1.archives-ouvertes.fr/hal-03328820

Submitted on 30 Aug 2021

HAL is a multi-disciplinary open access archive for the deposit and dissemination of scientific research documents, whether they are published or not. The documents may come from teaching and research institutions in France or abroad, or from public or private research centers.
L'archive ouverte pluridisciplinaire HAL, est destinée au dépôt et à la diffusion de documents scientifiques de niveau recherche, publiés ou non, émanant des établissements d'enseignement et de recherche français ou étrangers, des laboratoires publics ou privés. 


\title{
High-Resolution Technique for Near-Field Power Density Measurement Accounting for Antenna/Body Coupling at Millimeter Waves
}

\author{
Massinissa Ziane, Maxim Zhadobov, Senior Member, IEEE, and Ronan Sauleau, Fellow, IEEE
}

\begin{abstract}
This letter introduces a technique for the power density (PD) pattern measurement in the near field taking into account the antenna/body coupling at millimeter waves $(\mathrm{mmW})$. The proposed method employs a specifically designed structure reproducing the reflection coefficient from human skin. This structure is optimized to convert the absorbed PD into an infrared (IR) pattern, remotely recorded using a high-resolution IR camera for reconstruction of the PD distribution. As a validation example, numerical and experimental distributions are presented for a 4element patch antenna array and a conical horn antenna at 60 GHz. A very good agreement is demonstrated between simulations and measurements (correlation $>\mathbf{9 8 \%}$ ). The results suggest a strong potential of this technique for fast remote high-resolution PD measurements applied to characterization of wireless devices in vicinity of the human body.
\end{abstract}

Index Terms-Millimeter-wave measurements, antennas, tissue-equivalent models, power density, infrared thermography.

\section{INTRODUCTION}

$\mathrm{T}$ he increasing need in network capacity and high data rates has triggered an exponential interest to wireless applications at millimeter waves (mmW) [1]. In particular, the $60 \mathrm{GHz}$ band has been identified as highly promising and extremely attractive to support the rise of data traffic [2]. Wireless devices operating in this band will benefits from higher data rates, larger bandwidth, secure communications, and compact size [3]-[6].

Conventional near-field measurements at $\mathrm{mmW}$ are performed using probe scanning systems [7], [8]. However, this requires a long acquisition time as well as a relatively large separation distance between the antenna under test (AUT) and the acquisition probe for interferences mitigation.

Infrared (IR) thermography allows for remote high-spatialresolution (sub-mm) fast (typically several sec) power density (PD) pattern measurements, not achievable using standard probes (e.g., monopole or dipole, which do not measure details smaller than a wavelength). Furthermore, in contrast to standard electromagnetic (EM) probes, IR-based microwave

Manuscript submitted March 31, 2021; revised May 16, 2021; accepted June 01, 2021

This work was supported by the French National Research Program for Environmental and Occupational Health of ANSES (2018/2 RF/07) through NEAR 5G project. It was also partly supported by "Région Bretagne" (ARED program) and by the French Ministry of Higher Education and Research (MESR); by Brittany Region, Ministry of Higher Education and Research, measurements are broadband, isotropic, and polarization insensitive.

IR imaging has been used for temperature-mediated measurements of PD induced by a mmW source on a skinequivalent model [9], [10]. In [11], the IR thermography was employed to measure PD and specific absorption rate induced on the surface of a skin-equivalent model by an off-body patch antenna array [12], [13]. A methodology for measurement of the electric field using an absorption screen made of carbonloaded polymers and an IR camera was discussed in [14] for a patch antenna at $2.45 \mathrm{GHz}$, in [15] for a Ku-band horn antenna at $12-16 \mathrm{GHz}$, and in [16]-[18] for defects detection at microwaves.

When an antenna is located in the vicinity of a scatter, such as the human body, complex interactions occur leading to modification of the field distribution compared to the free-space radiation [19]. Therefore, for accurate PD characterization accounting for presence of a user, it is important to perform measurements under conditions where the AUT is perturbed in the same way as by the presence of the human body in realistic use case scenarios.

In this paper, we present a technique for high-spatialresolution PD pattern measurement in the near-field accounting for changes in the antenna radiation due to antenna/body interactions. To this end, we used a high-resolution IR camera and a specifically designed thin planar solid skin-equivalent structure emulating the reflection coefficient at the air/skin interface. The proposed technique is validated numerically and experimentally at $60 \mathrm{GHz}$ using a 4-elements patch antenna array and conical horn antenna.

\section{MEASUREMENT SET-UP}

The measurement set-up is represented schematically in Fig. 1. A continuous-wave $60-\mathrm{GHz}$ signal is generated by a highpower mmW generator (QuinStar, CA, USA). The power and frequency are controlled by a programmable power supply (Rohde \& Schwarz, Munich, Germany). The signal is

Rennes Métropole and Conseil Départemental, through the CPER Project SOPHIE/STIC and Ondes; by French National Center for Scientific Research (CNRS).

M. Ziane, M. Zhadobov, and R. Sauleau are with Univ Rennes, CNRS, Institut d'Electronique et des Technologies du numérique (IETR)-UMR 6164, F-35000 Rennes, France (e-mail: maxim.zhadobov@univ-rennes1.fr). 
transmitted to the AUT through a set of WR-15 rectangular waveguides. The input power of the AUT was measured using an Agilent E4418B power meter (Agilent Technologies, Santa Clara, CA, USA) and found to be equal to $3156 \mathrm{~mW}$. Note that in the proposed technique the power level should be high enough to obtain a high signal-to-noise ratio (SNR) and sufficient IR image contrast. For example, to achieve a SNR > $10 \mathrm{~dB}$ after $10 \mathrm{~s}$ of exposure, the input power should be at least $880 \mathrm{~mW}$ and $423 \mathrm{~mW}$ at $d=2 \mathrm{~mm}, 2365 \mathrm{~mW}$ and $1443 \mathrm{~mW}$ at $d=10 \mathrm{~mm}$ for 4 -elements patch array and conical horn antennas, respectively. Note that the minimum required input power also depends on the phantom thickness (in general, for a given phantom material a higher minimum power is required for thicker phantoms).

A X6540sc IR camera (FLIR Systems, Wilsonville, Oregon, USA) with the thermal sensitivity of $18 \mathrm{mK}$ and spatial resolution of $640 \times 512$ pixels is used to record the heating pattern dynamics on the upper surface of the phantom. The IR camera is located on the opposite side of the AUT, $15 \mathrm{~cm}$ from the phantom. The phantom, described in detail in section III, is designed in such a way that the PD distributions at both interfaces are almost identical (minimum correlation between the two sides is $99 \%$ [20]). The sequence of thermal images is recorded with a sampling rate of 50 frames per sec. The measurements are conducted inside a compact anechoic chamber covered by $\mathrm{mmW}$ absorbers (AN-73 Eccosorb, Emerson \& Cuming, Belgium) having free space reflectivity $>$ $17 \mathrm{~dB}$ in the $60 \mathrm{GHz}$ band.

For short exposure duration $\Delta t$ (in this study $\Delta t=3 \mathrm{~s}$ ), the heating pattern on the phantom ( $\mathrm{T}$ ) represents the PD distribution (with a theoretical correlation and maximum relative error within $99.8 \%$ and $3.27 \%$, respectively, for $\Delta t=3$ $\mathrm{s})$, which are related for plane-wave exposure as

$$
P D=\left.\frac{c \rho}{\sigma} \operatorname{Re}\left[\frac{1}{Z^{*}}\right] \frac{d T}{d t}\right|_{t=0},
$$

where $c, \rho, \sigma, Z^{*}$ are the heat capacity, mass density, electrical conductivity, and complex impedance of the phantom, respectively.

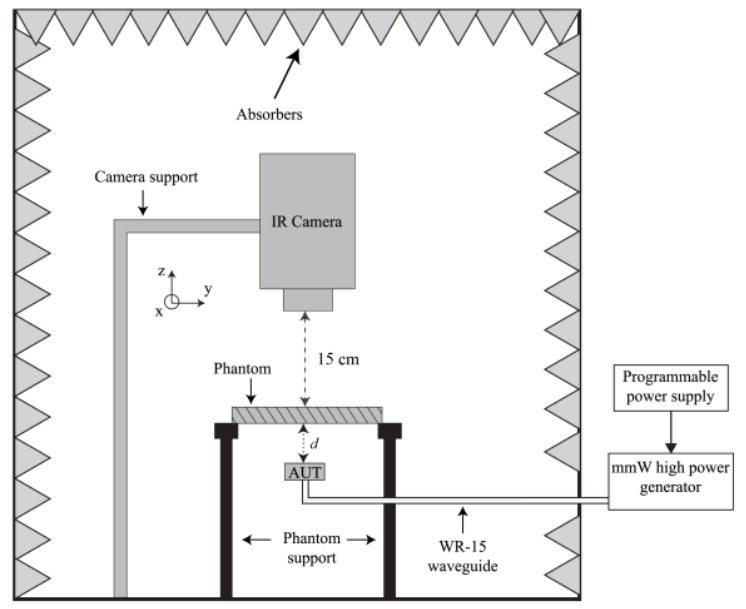

Fig. 1. Experimental set-up.

\section{PHANTOM}

To accurately reproduce the antenna/body interactions the lossy structure (referred as phantom), used to convert the EM power into heating, should have the same power reflection coefficient as that of human skin. Furthermore, the phantom should be as thin as feasible to maximize the transmission through the phantom and thus the temperature rise on its upper side. Moreover, the losses in the phantom should be high enough to ensure a measurable temperature (the higher the losses the higher is the SNR of the recorded heat profiles). Finally, as the temperature is recorded at the upper side of the phantom, the PD distributions at both sides should be as close as possible. Under these conditions, PD can be retrieved from the measurement of the heating pattern at the upper surface of the phantom.

To satisfy these criteria, we designed, optimized, and fabricated a planar solid phantom using carbon black powder and PDMS (low-loss dielectric) (Fig. 2a). The fabrication process is described in detail in [21]. In brief, PDMS (obtained by mixing silicone gel and curing agent) is stirred thoroughly with the carbon powder, then degassed under vacuum, and finally placed in an oven for two hours for drying at $110{ }^{\circ} \mathrm{C}$. The carbon concentration and phantom thickness were optimized to obtain a reflection coefficient approaching the one at the air/skin interface and sufficient transmission guaranteeing similar PD distributions at both sides in the 56.5-67 GHz range (Fig. 2b). The optimal values were found to be $40 \%$ and 2.5 $\mathrm{mm}$, respectively. Note that increasing the carbon concentration beyond this value would complicate fabrication of the phantom and reduce its homogeneity. The size of the phantom should be large enough to contain the entire field aperture (i.e., half-power bandwidth [8]) and avoid appearance of surface waves close to the phantom borders. Therefore, we used a $100 \mathrm{~mm} \times 100 \mathrm{~mm}$ phantom.

The complex permittivity of the carbon-PDMS phantom (CPDMS) was measured at $60 \mathrm{GHz}$ using the free-space transmission method as described in [21]. It was found to be equal to $\varepsilon_{r}=11.64-2.91 j$. The reflection coefficient is calculated analytically using Fresnel coefficients [22], [23] and computed numerically using the frequency-domain solver of CST Microwave Studio (Fig. 2c,d). Differences between the reflection coefficients of the dry skin and CPDMS phantom are within $10 \%$ for incidence angles $<50^{\circ}$ (Fig. 2c). For a phantom diameter of $100 \mathrm{~mm}$, this limitation in terms of angular range allows measurements up to $d=42 \mathrm{~mm}$ from the phantom for an omnidirectional source. This distance is extended for directive antennas (e.g., to $120 \mathrm{~mm}$ and $365 \mathrm{~mm}$ for a $2 \times 2$ patch array and conical horn antenna, respectively). 


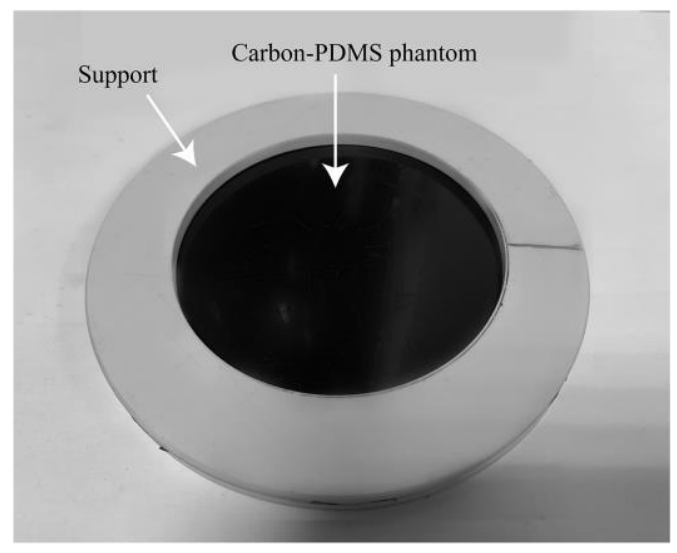

(a)

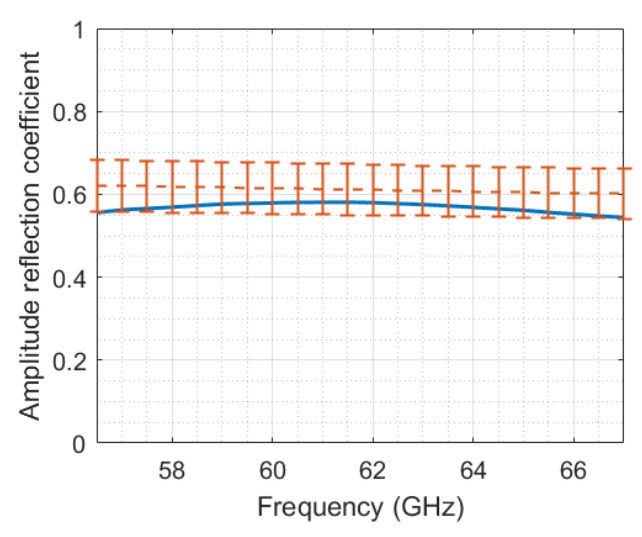

(b)

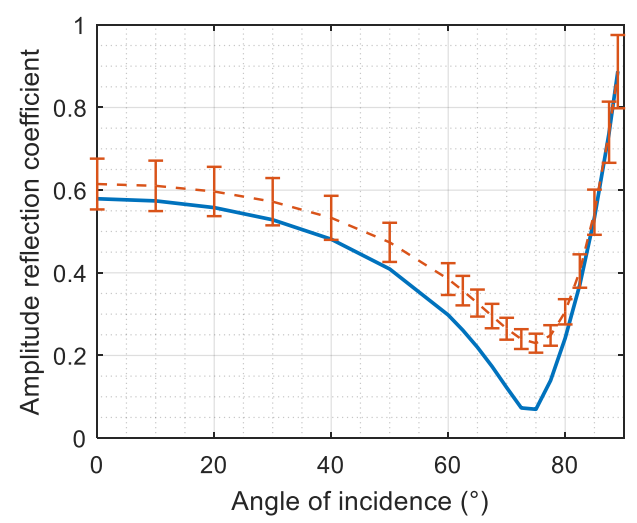

(c)

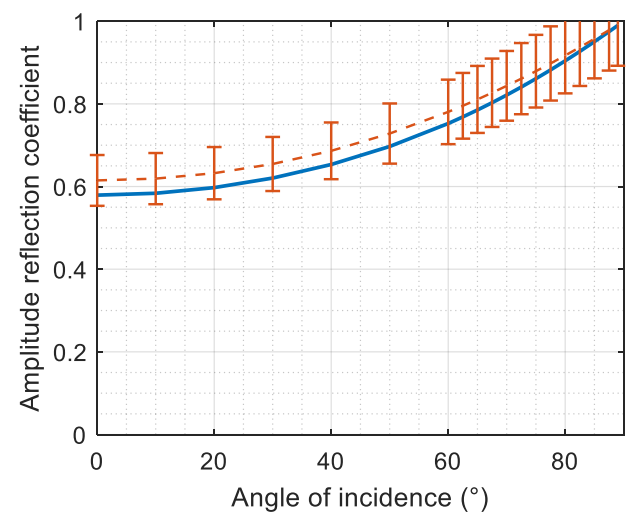

(d)
Fig. 2. Skin equivalent-phantom. (a) Fabricated prototype. (b) Amplitude reflection coefficient for normal incidence in the $56.5-67 \mathrm{GHz}$ range. Amplitude reflection coefficient at $60 \mathrm{GHz}$ for (c) parallel polarization (TM) and (d) perpendicular polarization (TE). CDPMS (blue solid line) and skin (orange dashed line). Error bars represent $+/-10 \%$ of the reference values.

\section{NUMERICAL SIMULATIONS}

The measured temperature distributions are compared to numerical results computed using the finite integration technique (FIT) implemented in CST Studio Suite. Open boundaries are used representing free-space conditions. The total number of mesh cells reaches about 29 million and 160 million for patch array and conical horn antennas, respectively. Convergence is reached by setting mesh cell size equal to 70 $\mu \mathrm{m}$ in the phantom and $200 \mu \mathrm{m}$ in the surrounding free-space. High-performance workstation with accelerators (Xeon Gold 6140, 768 Go RAM, NVIDIA Quadro GV100) is used for computations. Typical duration of a simulation is about $36 \mathrm{~min}$ and $263 \mathrm{~min}$ for patch array and conical horn antennas, respectively.

\section{EXPERIMENTAL VALIDATION AT $60 \mathrm{GHz}$}

We used two representative AUT: (1) a $2 \times 2$ patch antenna array with 11.9-dBi gain matched to $50 \Omega$ at $60 \mathrm{GHz}$ [11], (2) a V-band linearly-polarized conical horn antenna with $21.4 \mathrm{dBi}$ gain (QuinStar, CA, USA) (Fig. 3) connected to feeding rectangular waveguides using a waveguide-to-coax adapter and rectangular-to-circular transition, respectively.
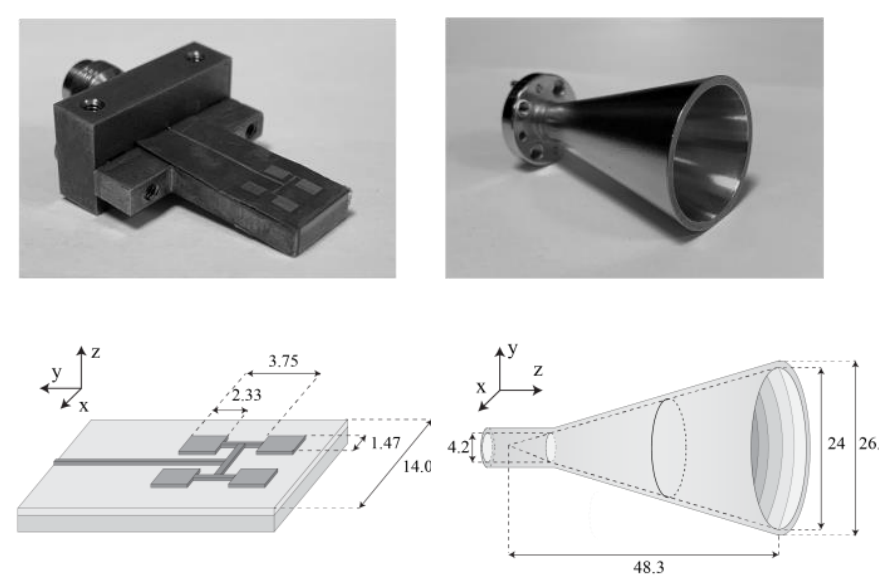

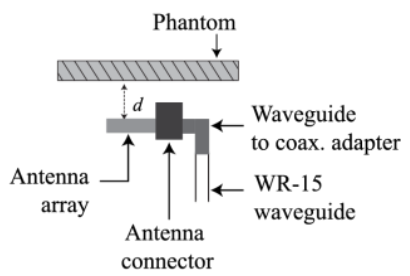

(a)

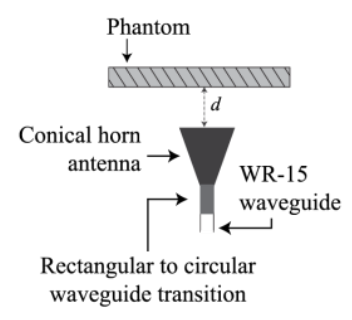

(b)
Fig 3. AUT: (a) patch antenna array, (b) conical horn. Fabricated prototypes (top), schematic (middle), and positioning in respect to phantom (bottom). Dimensions are in $\mathrm{mm}$.

To compare the simulated and measured distributions of PD, we used the correlation coefficient $r$ defined as [20] 


$$
r=\frac{\sum_{m} \sum_{n}\left(X_{m n}-\bar{X}\right)\left(Y_{m n}-\bar{Y}\right)}{\sqrt{\sum_{m} \sum_{n}\left(X_{m n}-\bar{X}\right)^{2} \sum_{m} \sum_{n}\left(Y_{m n}-\bar{Y}\right)^{2}}}
$$

where $X$ and $Y$ are the measured and simulated distributions, respectively, and $\bar{X}$ and $\bar{Y}$ are the mean values of $X$ and $Y$, respectively. The parameter $r$ is an indicator of how close the two relative distributions fit.

The PD distribution computed and measured for both AUT is shown in Fig. 4. The correlation of numerical and experimental distributions is $99.4 \%$ (at $d=6.5 \mathrm{~mm}$ ) for the patch antenna array (Fig. 4a) and $98 \%$ (at $d=3 \mathrm{~mm}$ ) for the conical horn antenna (Fig. 4c).

A very good agreement between numerical and experimental results is observed for the main lobes (Fig. 4b,d). A discrepancy between simulated and measured side lobes is attributed to the thermal noise (noise level equals to $-13.6 \mathrm{~dB}$ ). This discrepancy, mainly due to the thermal diffusion and low SNR of side lobes, can be reduced by increasing the power (thus enhancing the SNR) or by solving the inverse heat conduction problems [24]. Note that advanced post-processing schemes to enhance the PD reconstruction accuracy are out of the scope of this proof-of-concept study and constitute one of its perspectives.
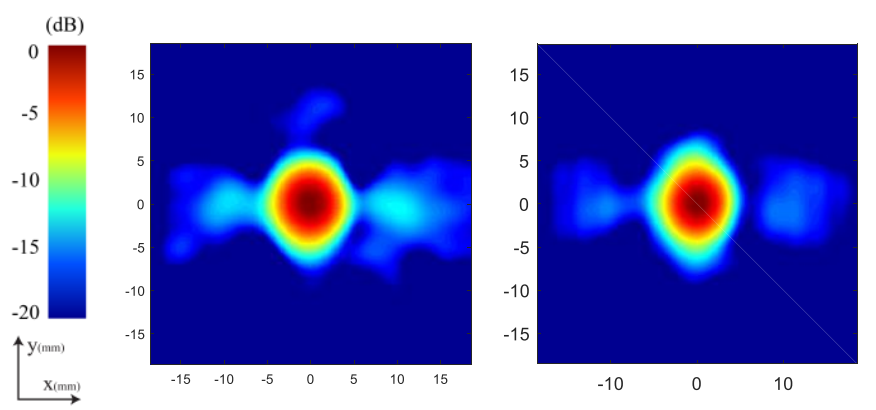

PD distributions: measured (left) and simulated (right).
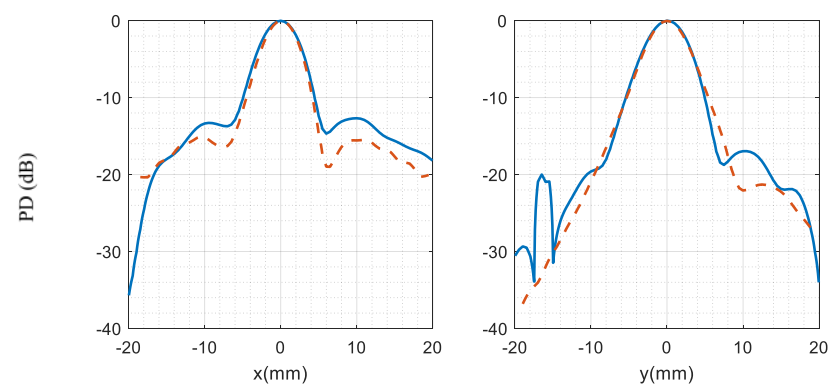

PD: 1-dimentional simulated (dashed curve) and measured (solid surve) along $\mathrm{x}$-axis $(y=0 \mathrm{~mm})$ (left), $\mathrm{y}$-axis $(x=0 \mathrm{~mm})($ right $)$.

(a)
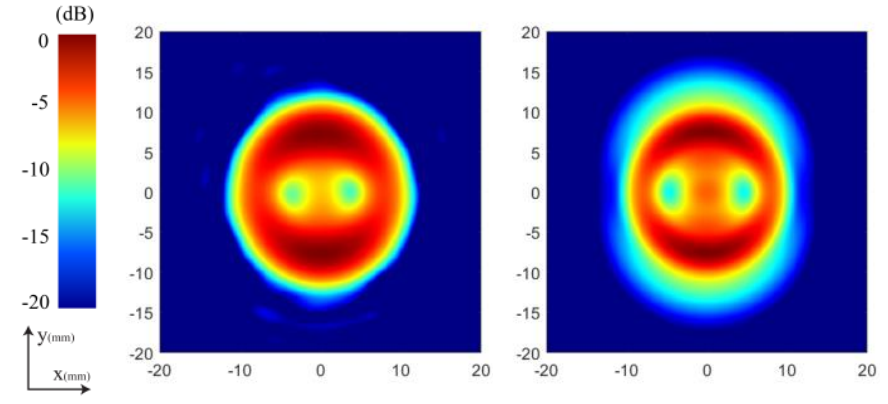

PD distributions: measured (left) and simulated (right).
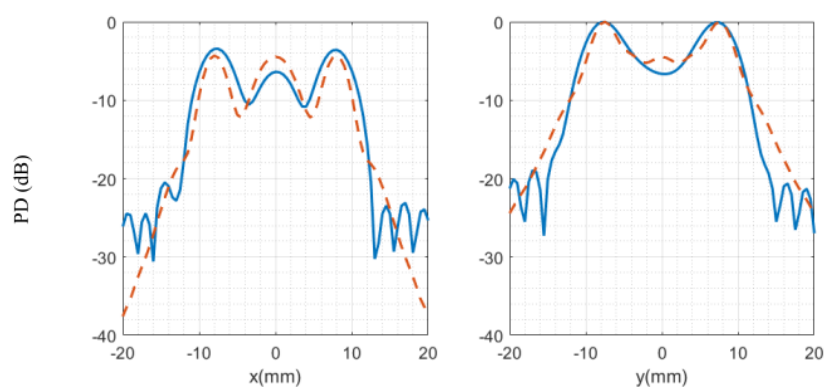

PD: 1-dimentional simulated (dashed curve) and measured (solid surve) along $\mathrm{x}$-axis $(y=0 \mathrm{~mm})$ (left), $\mathrm{y}$-axis $(x=0 \mathrm{~mm})$ (right).

(b)

Fig. 4. Simulated and measured PD for: (a) patch array antenna at $d=6.5 \mathrm{~mm}$, (b) conical horn antenna at $d=3.0 \mathrm{~mm}$.

\section{CONCLUSION}

In this paper, we presented a near-field technique for fast PD pattern measurement at $\mathrm{mmW}$ with micro-scale resolution accounting for the antenna/body coupling. Note that this technique can be also used for far-field measurements. As a part of the measurement system, we introduced, for the first time, a specifically designed solid lossy skin-equivalent structure for visualization and measurement of the heating pattern by remote IR imaging and reconstruction of the PD profile.

As an application example, numerical and experimental PD distributions were compared at $60 \mathrm{GHz}$ for a 4-elements patch antenna array and linearly polarized conical horn antenna. A very good agreement between simulations and measurements was demonstrated for the main lobes (correlation > 98\%). This proof-of-concept study suggests a strong potential of this technique for fast remote high-resolution PD measurements. It can be used for instance to characterize the near-field radiation pattern or the antenna performances in presence of a human body. Further improvements towards side lobes measurements using advanced IR thermography and post-processing schemes constitute one of the perspectives of this study. Moreover, knowledge of the phantom thermal characteristics may allow for retrieval of the absolute values of PD.

\section{REFERENCES}

[1] R. C. Daniels, J. N. Murdock, T. S. Rappaport, and R. W. Heath, "60 GHz Wireless: Up Close and Personal”, IEEE Microw. Mag., vol. 11, $\mathrm{n}^{\mathrm{o}}$ 7, p. 44-50, déc. 2010.

[2] "Cisco Visual Networking Index: Global Mobile Data Traffic Forecast Update 2014-2019 White Paper". [Online]. Available: www.cisco.com/c/en/us/solutions/collateral/service-provider/visualnetworking-index-vni/mobile-white-paper-c11-520862.html 
[3] J. Wells, "Faster than fiber: The future of multi-G/s wireless", IEEE Microw. Mag., vol. 10, nº 3, p. 104-112, mai 2009.

[4] A. Straiton, "The absorption and reradiation of radio waves by oxygen and water vapor in the atmosphere", IEEE Trans. Antennas Propag., vol. 23, n ${ }^{\circ}$, p. 595-597, juill. 1975.

[5] P. Rosenkranz, "Shape of the $5 \mathrm{~mm}$ oxygen band in the atmosphere", IEEE Trans. Antennas Propag., vol. 23, nº 4, p. 498-506, juill. 1975.

[6] A. Pellegrini and al., "Antennas and Propagation for Body-Centric Wireless Communications at Millimeter-Wave Frequencies: A Review [Wireless Corner]", IEEE Antennas Propag. Mag., vol. 55, $\mathrm{n}^{\circ}$ 4, p. 262-287, août 2013

[7] S. Gregson, J. McCormick, and C. Parini, Principles of Planar NearField Antenna Measurements. The Institution of Engineering and Technology, Michael Faraday House, Six Hills Way, Stevenage SG1 2AY, UK: IET, 2007.

[8] C. A. Balanis, Antenna theory: analysis and design, Fourth edition. Hoboken, New Jersey: Wiley, 2016.

[9] C. Leduc and M. Zhadobov, "Impact of Antenna Topology and Feeding Technique on Coupling With Human Body: Application to 60-GHz Antenna Arrays", IEEE Trans. Antennas Propag., vol. 65, $\mathrm{n}^{\circ}$ 12, p. 6779-6787, déc. 2017.

[10] A. K. Fall, P. Besnier, C. Lemoine, M. Zhadobov, and R. Sauleau, "Experimental Dosimetry in a Mode-Stirred Reverberation Chamber in the 60-GHz Band", IEEE Trans. Electromagn. Compat., vol. 58, $\mathrm{n}^{\circ}$ 4, p. 981-992, août 2016.

[11] N. Chahat, M. Zhadobov, L. Le Coq, S. I. Alekseev, and R. Sauleau, "Characterization of the Interactions Between a 60-GHz Antenna and the Human Body in an Off-Body Scenario", IEEE Trans. Antennas Propag., vol. 60, no 12, p. 5958-5965, déc. 2012.

[12] "Guidelines for Limiting Exposure to Electromagnetic Fields (100 kHz to $300 \mathrm{GHz}$ ) ", Health Phys., vol. 118, nº 5, p. 483-524, mai 2020.

[13] "IEEE Standard for Safety Levels with Respect to Human Exposure to Electric, Magnetic, and Electromagnetic Fields, $0 \mathrm{~Hz}$ to $300 \mathrm{GHz}$,, IEEE.

[14] K. Muzaffar, S. Tuli, and S. Koul, "Infrared thermography for electromagnetic field pattern recognition", in IEEE MTT-S International Microwave and RF Conference, New Delhi, India, déc. 2013, p. 1-4.

[15] D. Prost, F. Issac, and M. Romier, "Imaging electric and magnetic near field of radiating structures by infrared thermography", in 2019 International Symposium on Electromagnetic Compatibility - EMC EUROPE, Barcelona, Spain, sept. 2019, p. 311-314.

[16] P. Levesque, P. Brémond, J.-L. Lasserre, A. Paupert, and D. L. Balageas, "Performance of FPA IR cameras and of their improvement by time, space and frequency data processing: Part II - Application to the thermographic measurement of microwave fields", Quant. InfraRed Thermogr. J., vol. 2, nº 2, p. 237-250, déc. 2005.

[17] C. Pradere and al., «Photothermal converters for quantitative 2D and 3D real-time TeraHertz imaging », Quant. InfraRed Thermogr. J., vol. 7, no 2, p. 217-235, déc. 2010.

[18] D. Balageas and al., "Thermal (IR) and Other NDT Techniques for Improved Material Inspection", J. Nondestruct. Eval., vol. 35, n 1, p. 18, mars 2016

[19] M. Ziane, R. Sauleau, and M. Zhadobov, "Antenna/Body Coupling in the Near-Field at $60 \mathrm{GHz}$ : Impact on the Absorbed Power Density", Appl. Sci., vol. 10, n 21, p. 7392 , oct. 2020.

[20] J. P. Holman, Experimental methods for engineers, 8th ed. Boston: McGraw-Hill/Connect Learn Succeed, 2012.

[21] A. R. Guraliuc, M. Zhadobov, O. De Sagazan, and R. Sauleau, "Solid Phantom for Body-Centric Propagation Measurements at $60 \mathrm{GHz}$ ", IEEE Trans. Microw. Theory Tech., vol. 62, nº 6, p. 1373-1380, juin 2014.

[22] D. M. Pozar, Microwave engineering, 4th ed. Hoboken, NJ: Wiley, 2012.

[23] F. Mangini and F. Frezza, « On zero-reflection and zero-transmission of a stratified lossy medium », in 2016 URSI International Symposium on Electromagnetic Theory (EMTS), Espoo, Finland, août 2016, p. 755-758.

[24] J. Taler and P. Duda, Solving direct and inverse heat conduction problems. New York; Berlin: Springer, 2006. 